\title{
Dinámica temporal de las actividades económicas en el estado de Chihuahua, México
}

\author{
Olga Correa Miranda \\ Universidad Nacional Autónoma de México \\ geog_olg@comunidad.unam.mx
}

Recepción: 16 de abril de 2010 / Revisión: $1^{\circ}$ de octubre de 2010

Aceptación: 4 de febrero de 2011 / Publicación: diciembre de 2011

\section{RESUMEN}

El objetivo de esta investigación es dar a conocer los principales eventos históricos que dieron pauta a la actual configuración territorial de las actividades económicas en el estado de Chihuahua. Se exponen las posturas teórico-metodológicas que constituyeron la base para la reconstrucción espacio-temporal. Posteriormente, se efectúa la caracterización de las actividades económicas que se gestaron y desarrollaron en Chihuahua, mediante la identificación y reconocimiento de cuatro etapas históricas.

Palabras clave: configuración económico-temporal, matriz geo-histórica, Estado de Chihuahua, México.

\section{Temporal Dynamics of Economic Activity in the State of Chihuahua, Mexico}

\begin{abstract}
The aim of this paper is to disclose the main historical events that conditioned the current territorial configuration of economic activities in the State of Chihuahua. The theoretical and methodological stances that constitute the base for a time-space reconstruction are expounded. Subsequently, a characterization is made of the economic activities that were generated and developed in Chihuahua, by means of the identification and recognition of four historical stages.
\end{abstract}

Keywords: Economic-temporary configuration, geo-historical matrix, State of Chihuahua, Mexico.

SUMARIO: 1. Introducción 2. Consideraciones teórico-metodológicas. 3 Aspectos históricos relacionados con la configuración económica del estado de Chihuahua. 3.1. Septentrión como zona de frontera de contención geopolítica. La búsqueda de minerales y las primeras manifestaciones urbanas (15211780). 3.2. Auge económico del estado de Chihuahua. Concentración de capital y diversificación funcional de las ciudades (1780-1907). 3.3. Crisis económica del estado de Chihuahua. Polarización de la riqueza hacia grupos de poder (1907 a 1960). 3.4. Chihuahua como destino de inversión extranjera directa orientado hacia el desarrollo del sector industrial (1960 - actualidad). 4. Conclusión 5. Referencias bibliográficas. 


\section{INTRODUCCIÓN}

El estado de Chihuahua, localizado en la porción norte-centro de la República Mexicana, es la entidad más extensa y representa el 12,6\% de la superficie total del país. Limita al norte con Estados Unidos de América, en una franja fronteriza que mide poco más de $900 \mathrm{~km}$; al oeste con el estado de Sonora; al sur con Durango y Sinaloa; y al este con el estado de Coahuila. La ubicación geográfico-estratégica de Chihuahua lo ha convertido en una de las principales puertas para el intercambio comercial entre México, Estados Unidos y Canadá; su mano de obra calificada y sus valiosos recursos naturales han sido factores decisivos para el desarrollo económico del estado.

Actualmente se constituye como una de las entidades que más aportan al producto bruto interno nacional y como un destino de inversión extranjera directa, donde el fuerte desarrollo del sector industrial ha generado, a su vez, la expansión de la actividad comercial y de los servicios. Sin embargo, no hay una distribución proporcionada de la actividad económica en toda la entidad; se observa una fuerte polarización en la distribución del ingreso y la concentración de la población en las principales ciudades del estado. Estas circunstancias, aunadas a la influencia de factores físico-geográficos, históricos, económicos, políticos y culturales han dado lugar a la configuración de espacios económicos disímiles.

Así, esta investigación tiene por objetivo revelar los eventos históricos más relevantes que acontecieron en el actual territorio chihuahuense y que ayudan a explicar su actual estructura económica.

\section{CONSIDERACIONES TEÓRICO-METODOLÓGICAS}

Las posturas teórico-metodológicas que constituyen la base para la interpretación y caracterización económica del estado de Chihuahua se exponen a continuación:

El tiempo, visto como un proceso histórico, es una dimensión fundamental para cualquier análisis que tenga que ver con la sociedad; el espacio es la proyección de la sociedad, el cual sólo puede ser explicado desentrañando su estructura y su funcionamiento; el análisis histórico de las bases de los modos de producción de la formación social es indispensable para aproximarse a la realización de cualquier estudio espacial ${ }^{1}$.

Asimismo, el espacio, considerado como un mosaico de diferentes épocas, sintetiza, por una parte, la evolución de la sociedad, y, por otra, explica situaciones que se presentan en la actualidad. Existen elementos del espacio que son intangibles sobre el territorio y decisivos para entender los procesos y, la única forma de recuperarlos es sumar la visión histórica al análisis².

\footnotetext{
${ }^{1}$ GÓmez, 1982, p. 150.

2 SAntos, 1985, pp. 21-24.
} 
La introducción de lo temporal en el estudio de la organización del espacio implica consideraciones de una dimensión muy amplia; esto es, de escala mundial pues la situación actual depende, en buena medida, de influencias impuestas. Algunos elementos ceden su lugar, completa o parcialmente, a otros de su misma clase, aunque más modernos; otros, en cambio, resisten a la modernización. En muchos casos, elementos de diferentes periodos coexisten o pueden desaparecer sin sucesión, y otros completamente nuevos pueden llegar a establecerse. Puede decirse que cada sistema temporal coincide con un periodo histórico y dicha periodización ofrece las claves para entender las diferencias o las similitudes entre lugares y distintas escalas. Con la identificación de etapas o periodizaciones es posible explicar la historia, las formas de organización y articulación del espacio, así como los grados de desarrollo y dependencia ${ }^{3}$.

Así, mediante una matriz geo-histórica, es posible revelar etapas relacionadas, en forma directa, con la dinámica temporal de un fenómeno determinado. En este sentido, los cortes temporales inherentes a la historia del Estado de Chihuahua sólo representan una referencia temática dentro del conjunto de conocimientos que deben ser tomados en cuenta. Esta inversión investigativa se conforma como una amalgama sintetizada del trabajo de los historiadores y se codifica de acuerdo con las etapas sociopolíticas reconocidas por la sociedad. Asimismo, durante el empleo de este método se posibilita la revelación de conocimientos nuevos que pueden ser representados en mapas ${ }^{4}$.

\section{ASPECTOS HISTÓRICOS RELACIONADOS CON LA CONFIGURACIÓN ECONÓMICA DEL ESTADO DE CHIHUAHUA}

A través de su historia social, Chihuahua ha sufrido cambios que han influido de manera decisiva en su conformación económico-territorial. Es de interés del presente trabajo precisar los factores económicos básicos de la formación regional de la entidad, tales como: actividades productivas, infraestructura, inversiones, proceso de urbanización, principales actores, los cuales se reflejarán a través de las etapas geográfico-históricas.

Los cortes temporales de las etapas geo-históricas que aquí se enmarcan responden al apogeo o decadencia de las actividades económicas privilegiadas por políticas que incidieron en el territorio chihuahuense, lo que conllevó a cierto estado de bienestar o de pobreza que sobrellevaron los habitantes del estado. Asimismo, constituyen un reflejo directo de los principales hechos históricos que enmarcaron la vida económica, social y política del norte del país.

\footnotetext{
${ }^{3}$ Ibidem.

${ }^{4}$ Propin, 2003, pp. 118-125.
} 


\subsection{Septentrión como zona de frontera de contención geopolítica. La búsqueda de minerales y las primeras manifestaciones urbanas (1521-1780)}

No obstante que las primeras expresiones económicas de la entidad se llevaron a cabo en años anteriores a este periodo ${ }^{5}$, los factores económicos básicos que determinaron su formación regional se inician de manera decisiva en la etapa colonial. El poblamiento de las regiones septentrionales se llevó a cabo por la Corona española con el objeto de reafirmar su derecho de dominio sobre el norte del país, frente al avance de la colonización anglosajona y de los intereses de franceses y rusos, quienes durante el siglo XVIII ejercían presión sobre los límites de la frontera española. Además, el poblamiento respondió al deseo de terminar con los continuos ataques

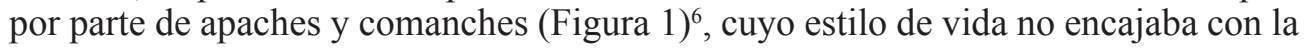
cosmovisión de los conquistadores. Los apaches no entendían el afán de acumulación de bienes materiales, y tampoco que un ser humano pudiera apropiarse de la tierra o de las aguas con exclusión de los demás. Luchaban por preservar una forma de vida que exigía el desplazamiento libre y sin barreras para localizar al bisonte o al venado, y demandaban también la aceptación del pillaje como recurso legítimo de sobrevivencia. De allí el hecho de que se desataran una serie de guerras indias de carácter cruento y larga duración 7 . Es así como el gobierno español fijó una serie de medidas estratégicas militares y políticas para controlar y someter esas rebeliones, para lo cual conformó una serie de presidios que funcionaron como puestos de resguardo para enfrentar a los grupos susceptibles de cristianizarse, y para proteger las comunicaciones entre el centro del país y los minerales recién descubiertos, así como a las haciendas y las misiones ${ }^{8}$.

\footnotetext{
${ }^{5}$ Los primeros pobladores del solar chihuahuense llegaron en épocas muy remotas. Sus vestigios corresponden a los de grupos conocidos como culturas del desierto y consisten en artefactos utilizados para la caza y la recolección. Destaca aquí la Cultura Paquimé, hoy denominada Casas Grandes, que llegó a ser la más importante en lo que se conoce como Aridoamérica. Su apogeo data entre 1200 y 1300 d. C. y su decadencia hacia 1450 d. C. Esta cultura logró un desarrollo socioeconómico-regional que le permitió ejercer influencia dentro de un amplio territorio que abarcó Chihuahua, Sonora, Arizona y Nuevo México, así como establecer relaciones comerciales de gran amplitud hacia Mesoamérica, con una red de intercambio de más de $2.000 \mathrm{~km}$ de objetos elaborados con cobre, turquesas y conchas, entre otros. Paquimé fue claramente una ciudad compleja que manifestó una estratificación social con especialistas desde los ámbitos sacerdotales hasta los artesanales. Fue un centro tanto ceremonial como de acopio de manufactura. Se ha calculado que el área total del sistema cultural de la cultura Casas Grandes abarcó cerca de $85.000 \mathrm{~km}^{2}$ donde se distribuía la mayor parte de la población que residía en cientos de asentamientos menores dedicados a la producción agrícola. AlmadA - Chávez, 1987, pp. 3-4; De LA FUENTE, 1994, pp. 141-142.

${ }^{6}$ Lloyd, 2001, p. 6; Garcí, 2001, pp. 63, 65.

${ }^{7}$ Orozco, 1992, pp. 13-31.

${ }^{8}$ Gerhard, 1996, p. 46; Almada, 1927, pp. 43-44.
} 

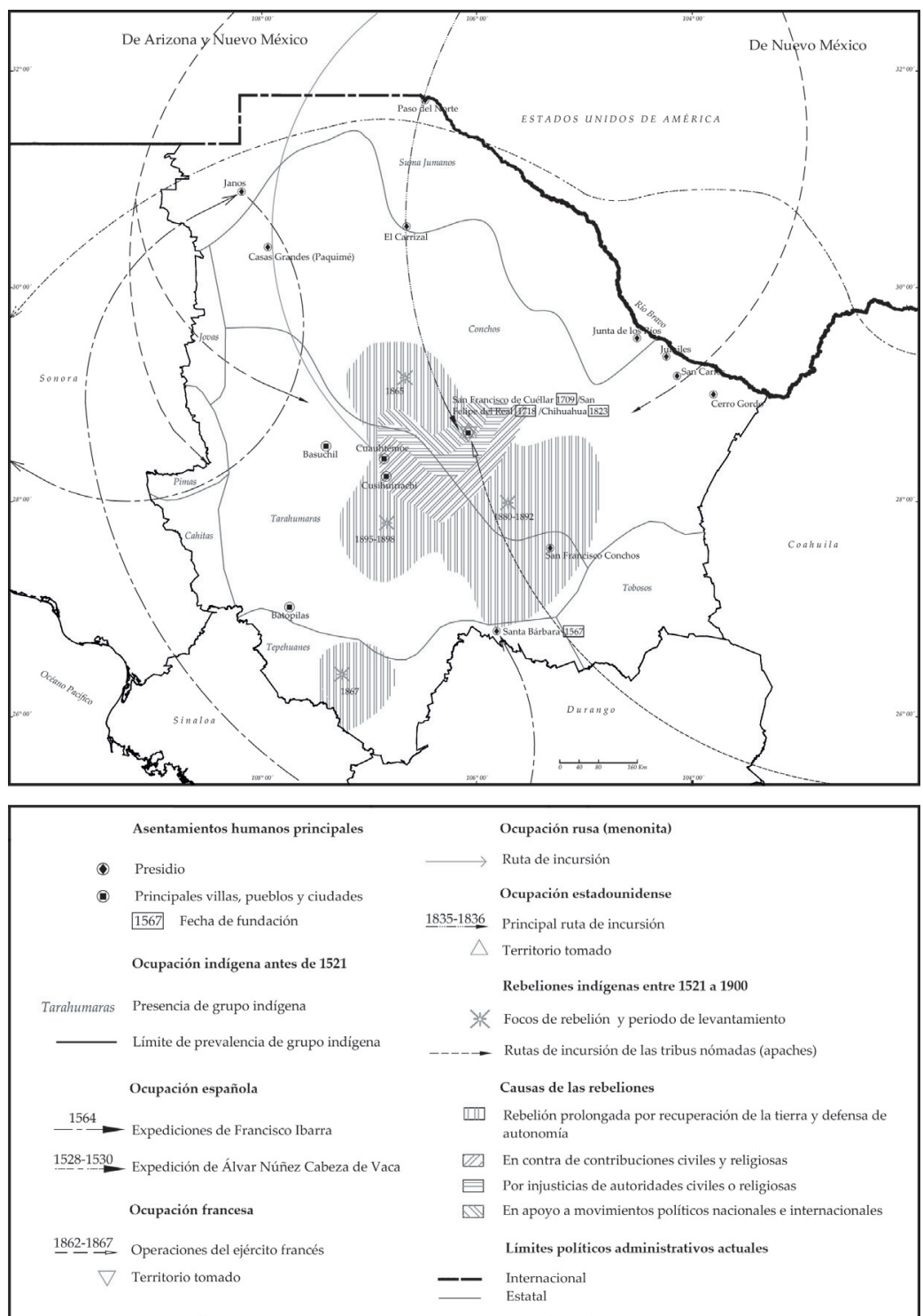

Fig 1. Chihuahua: ocupación territorial y rebeliones rurales, 1521-1900

Fuente: elaboración con basada en Vázquez, 1990; Camelo, et. al. 1990; Hernández, 1966.

Tanto los presidios, como los reales de minas, las haciendas y las misiones sirvieron como elementos de arraigo y consecuente poblamiento del norte del país. A veces el emplazamiento de un presidio ocurría en un terreno compartido por una misión o por una ciudad o villa española, que en conjunto conformaban un enclave defensivo de fundaciones complementarias. Los soldados de los presidios generalmente lleva- 
ban a sus familias consigo y adquirían tierras en las inmediaciones de sus plazas, lo que a la larga propiciaba que se quedaran en la región en calidad de colonos. Por su parte, las misiones constituían campamentos de cazadores-recolectores, quienes participaban en las experiencias de la vida sedentaria y religiosa que se les inculcaba ${ }^{9}$. La misión poseía tierras propias que cubrían las necesidades primarias de quienes se asentaban en ella, y el excedente de la cosecha se vendía a los presidios cercanos. Constituía también una fuente de mano de obra que surtía de trabajadores a las haciendas en tiempos de siembra y cosecha. Dada la importancia agrícola-ganadera que llegaron a adquirir, se tornaron en pueblos permanentes que más tarde constituirían ciudades intermedias. Sin embargo, las actividades agropecuarias que se generaban en grandes zonas del norte no ofrecían suficientes atractivos económicos a los colonizadores pues, de hecho, la intensidad con que se realizó la colonización estuvo en función de la búsqueda y explotación de recursos minerales ${ }^{10}$.

En términos generales, las condiciones sociales que imperaron en este periodo fueron críticas para los habitantes del estado. Por un lado, se vivieron situaciones de zozobra para la población indígena, que estuvo siempre a merced de los intereses económicos de los colonizadores. Posteriormente, los habitantes de los nuevos asentamientos, si bien fueron favorecidos por las condiciones de riqueza que les brindaba el territorio, también estuvieron a merced de constantes ataques efectuados por los grupos que se resistían a la nueva forma de vida impuesta.

\subsection{Auge económico del estado de Chihuahua. Concentración de capital y diversificación funcional de las ciudades (1780-1907)}

De 1780 a 1907 Chihuahua vive una etapa de consolidación y crecimiento hasta alcanzar un auge económico y urbano derivado de la explotación de sus recursos. Fue en esta fase cuando se gestó la estructura urbana de la actualidad ${ }^{11}$.

Los centros de población, como Parral y Chihuahua, ven aparecer gradualmente la diversificación y la ampliación de sus funciones. Se establecen asentamientos donde con anterioridad existían presidios, como en el caso de Janos y Juárez (Figura 2). Se vive en la entidad la reorganización de la vida urbana, la cual empieza a aceptar la actividad comercial con mayor amplitud y se advierte que la riqueza no está solo en la plata sino que existen otros productos ${ }^{12}$.

\footnotetext{
${ }^{9}$ Ibídem, pp. 43, 47.

${ }^{10}$ Carrera, 1989 citado por García, 2001, p. 92; EnríQuez, 1988, p. 48.

${ }^{11}$ García, 2001, p. 98.

${ }^{12}$ Ibídem, p. 95.
} 

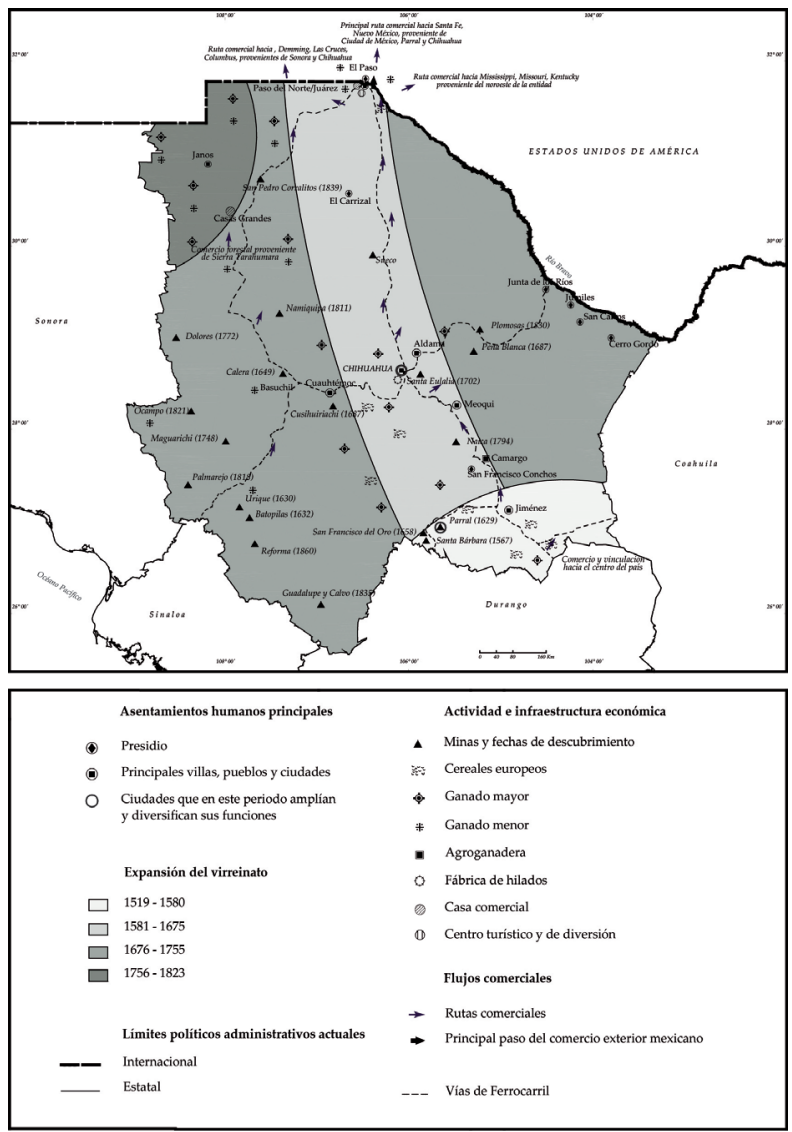

Fig 2. Chihuahua: ocupación territorial española y actividades económicas, siglo XVI-XIX Fuente: elaboración con basada en Consejo de Recursos Minerales, 1992; Carrera, op. cit; Lloyd, Op. cit.

Los cambios estructurales que sufre la economía del mundo durante la segunda mitad del siglo XIX, en la que los países más industrializados extienden su radio de influencia económica y política por todo el planeta, a través de corporaciones industriales, comerciales y financieras, influyen en la consolidación y el desarrollo de México por la inversión extranjera y el desarrollo de ciertas actividades industriales. Todo lo anterior hace que los estados fronterizos del norte del país reciban un gran impulso, incluyendo Chihuahua ${ }^{13}$.

En 1824 Chihuahua adquiere su categoría política como entidad federativa. En 1848 pierde una parte de su territorio a favor de Texas y, cinco años después, sufre su última modificación territorial al ceder otra parte de su extensión a Nuevo México (Figura 3) ${ }^{14}$.

${ }^{13}$ Ibidem, p. 98.

${ }^{14}$ Orozco, 1991, p. 6. Las políticas centralistas han incidido directamente en las condiciones económicas del norte de México. A lo largo de las etapas histórico-económicas que aquí se presentan, se han gestado hechos como la pérdida de territorio a consecuencia del abandono político-social y del 


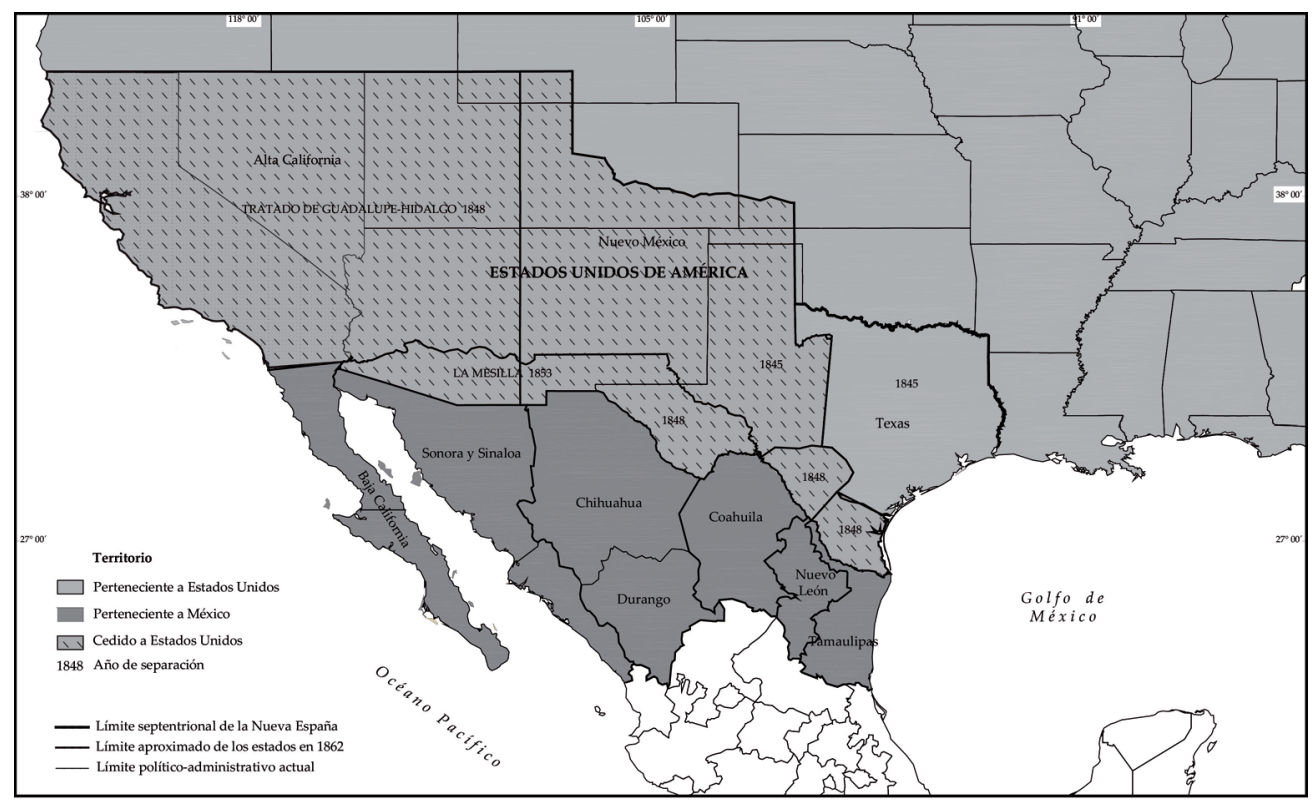

Fig 3. División territorial del norte de la República Mexicana, 1862 Fuente: elaboración con basada en Commons, 1990.

Para el censo de 1900, la entidad reportó un total de 327.748 habitantes distribuidos en una superficie de $233.000 \mathrm{~km}^{2}$, arrojando una densidad promedio de 1,4 hab/ $\mathrm{km}^{2}$. Figuraban ya como ciudades: Chihuahua, Juárez, Camargo, Guerrero, Hidalgo del Parral y Jiménez. Se consideraban cuatro pueblos: Janos, Aldama, Namiquipa y San Andrés; una villa (Meoqui) y un mineral (Batopilas). El resto de la población, eminentemente rural, quedó diseminada en 2.466 localidades menores, de tal manera que el $26 \%$ de la población se ubicó en tan sólo $0,4 \%$ de las localidades y en el 0,01\% de la superficie territorial del estado. Se comenzaban a generar flujos migratorios intraestatales por la acción ejercida desde las ciudades y también a la frontera por las ventajas comerciales; el proceso urbano inició una concentración de población, de instrumentos de producción, de inversión y de servicios. Las actividades productivas se fortalecen y dinamizan; la mano de obra se concentra en los sectores primario y secundario: en el primero, se integran 36.000 habitantes $(71 \%$ de la población económicamente activa -PEA-), la mayoría en faenas agropecuarias; en el secundario trabajaban 14.595 pobladores, 10.857 de los cuales se desempeñaban como obreros en las minas (21\% de la PEA) y 3.728 (el $8 \%$ ) en la industria ${ }^{15}$.

poco interés por parte del gobierno hacia la región septentrional. Actualmente, residuos de ese modelo de organización se ven reflejados en un poder centralizador de recursos hacendarios, en vez de constituirse en un equitativo distribuidor de facultades jurídicas e ingresos fiscales para los estados de la República, a pesar de que en el discurso oficial se comente lo contrario.

\footnotetext{
${ }^{15}$ García, 2001, p. 99.
} 
En cuanto a la actividad agropecuaria, se consolidan los elementos monopólicos de producción, como los latifundios agrícolas y ganaderos, las zonas boscosas, los centros mineros y los industriales, que generaron comercio intensivo y servicios. Diecisiete latifundistas acaparan $41 \%$ de las tierras; a partir de la instrumentación de la ley de 1.905 , la desamortización de las tierras comunales de Chihuahua fortaleció a los más adinerados, habituados a la propiedad privada sobre sus terrenos de cultivo, así como al usufructo colectivo de los recursos básicos de la comunidad. La combinación de esos factores les permitía lograr no sólo la subsistencia, sino desarrollar una lucrativa producción para el mercado regional, y acumular para 1904, en el noroeste del estado, varias haciendas ganaderas ${ }^{16}$.

Se construye la red ferroviaria estatal ${ }^{17}$ con una visión estratégica; se favorecen algunos territorios para comunicar zonas de explotación con los centros urbanos y la frontera. Para 1885 por El Paso fluía el 75\% del comercio exterior mexicano, lo que convirtió a esta ciudad en el principal paso mercantil de México. Este hecho marcó un cambio radical en la orientación del comercio exterior mexicano, ya que anteriormente a esta fecha se encaminaba hacia Veracruz y los mercados europeos. A partir de 1885 en adelante Estados Unidos sería el principal destino para los productos mexicanos. Durante el Porfiriato, los estados norteños, geográficamente más cercanos al vecino del norte, orientaron buena parte de su producción minera, forestal y agropecuaria a satisfacer la demanda estadounidense ${ }^{18}$.

Asimismo, el ferrocarril Río Grande-Sierra Madre-Pacífico posibilitó el desarrollo económico de la región noroeste, y sus principales productos tuvieron circulación hacia la frontera y al centro del país. Esta ruta promovió la apertura de una explotación extensiva de la zona semidesértica antes virgen y virtualmente desaprovechada. Casas Grandes se convirtió en el centro comercial de la zona y se inició la apertura económica de la sierra chihuahuense, lo que significó un gran impulso regional ${ }^{19}$.

En 1884, al noroeste de la entidad, 21 minas de oro, plata, plomo y hierro se encontraban en operación, algunas de ellas de capital estadounidense ${ }^{20}$, como La Can-

${ }^{16}$ LLoyd, 2001, p. 228; García, 2001, p. 100. Luis Terrazas y otros empresarios de capital estadounidense, inglés y mexicano eran los principales dueños de haciendas ganaderas del noroeste de la entidad. A principios del siglo XX, el grupo Terrazas tenía inversiones prácticamente en todas las ramas de la economía y mostraban un alto grado de organización empresarial. OROzCO, 1991, pp. 8-9.

${ }^{17}$ El Ferrocarril Central Mexicano en su trayectoria desde la ciudad de Chihuahua hasta El Paso, Texas, recorría un total de 360 kilómetros. En 1881 se logró comunicar la capital estatal directamente con el Distrito Federal y con la red ferroviaria del centro del país. La línea completa desde Ciudad Juárez a Ciudad de México contaba con una extensión de 1.970 kilómetros. El Central Mexicano fue el sistema ferroviario más importante del país, pues conectaba El Paso con siete de las principales líneas de los Estados Unidos. Lloyd, 2001, p. 97.

${ }^{18}$ Ibídem, p. 98; García, 2001, p. 101.

${ }^{19}$ LLOYD, 2001, p. 112.

${ }^{20}$ Desde finales del siglo pasado, la inversión estadounidense en la minería del estado fue más que significativa: en 1890 su inversión en propiedades del ramo en el país llegaba a 125.000.000; en 1907, a 800.000. De las 13 compañías mineras de aquella nacionalidad que había en México en 1868, la cifra subió a 840 en 1907; para 1910 los estadounidenses eran dueños del 75\% de los yacimientos redituables del país. En 1902 había por lo menos 45 compañías de esa nacionalidad con intereses mineros en Chihuahua; en 1907 se contaban con 167 estadounidenses y 24 inglesas, en 1911 había 325 
delaria Minning Company, que estaba clasificada en 1905 como la primera productora de plata de Chihuahua, con un rendimiento de $13,5 \%$ de la producción minera total del estado ${ }^{21}$.

De 1902 a 1906 se expandieron las actividades mineras y la producción llegó a sus niveles más altos; la vía del ferrocarril Río Grande-Sierra Madre-Pacífico se prolongó hacia la Sierra y se inició la explotación de recursos forestales en gran escala, el comercio estaba en pleno auge y el flujo de capital extranjero era constante.

Debido a la especialización propiciada por el progreso, los centros mayores cambian sus patrones de funcionamiento. Así, Juárez, antes centro agrícola, se convierte en próspero centro de turismo y diversiones. Chihuahua consolida su industria, servicios y administración pública. Parral, siempre minero, apoya con comercio y servicios al conjunto de minerales y pequeñas localidades que se ubican en su área de dominio. Camargo aprovecha el auge algodonero, con lo que asegura la industria textil y despepitadora. Jiménez, único centro agrícola que sobrepasaba los 5.000 habitantes, contrae su crecimiento ${ }^{22}$.

Entre 1904 y 1909 no sólo aumentó cuantitativamente el comercio, sino que también se diversificó. A partir de este momento se generaron en la región grandes comercios mayoristas de capital extranjero que invirtieron en otras regiones del estado, dando lugar, entre otras cosas, a una fábrica de hilados en Chihuahua y una casa comercial en Ciudad Juárez, con una sucursal en Casas Grandes y una hacienda agroganadera en Camargo. La zona noroeste quedaba incluida dentro del área de afluencia de dos importantes rutas comerciales de trigo, maíz, carne seca, nuez, chile, barriles de sotol, resinas de pino, lana de borrego y ganado vacuno: la de Parral-ChihuahuaPaso del Norte-Santa Fe-Nuevo México, que ligaba rutas comerciales de la cuenca del Mississippi, Missouri y Kentucky, y la llamada ruta de Sonora, que conectaba a la ciudad de Chihuahua con San Buenaventura, Janos, Galeana, Casas Grandes, Nuevo México, Demming, Las Cruces y Columbus ${ }^{23}$.

En términos sociales, en este periodo se observan mejores niveles de vida para la población que vivía en los principales asentamientos de la entidad, dada la diversificación y la ampliación de funciones de estos centros. En contraparte, los habitantes de las zonas rurales (a excepción de grandes latifundistas agrícolas-ganaderos e industriales forestales y mineros) resultaron ser el sector menos favorecido en la nueva dinámica económica.

compañías extranjeras que operaban en el estado. Además, en 1907 los extranjeros poseían el 75\% de las operaciones mineras de la entidad. Durante este mismo periodo, las 10 compañías extranjeras más grandes de Chihuahua, entre ellas La Candelaria, monopolizaban el 70\% de la producción. La Candelaria Mining Company era dueña del complejo minero de San Pedro y poseía también 464.200 hectáreas de tierras ganaderas y forestales. Operaba en una vasta zona que se extendía desde el norte de Casas Grandes hacia el oeste, hasta la cima de la Sierra Madre, limítrofe con el estado de Sonora. En 1897 la Candelaria Mining Company construye el ferrocarril Río Grande-Sierra Madre-Pacífico que iba desde su planta de fundición en Ciudad Juárez hasta sus minas de San Pedro, ruta que pasaba por el recién abierto distrito minero de El Sabinal, al este de Ascensión. Lloyd, 2001, p. 60.

${ }^{21}$ Ibidem, p. 61.

${ }^{22}$ García, 2001, p. 104.

${ }^{23}$ Lloyd, 2001, p. 95. 


\subsection{Crisis económica del estado de Chihuahua. Polarización de la riqueza hacia grupos de poder (1907 a 1960)}

En 1907 se vive un periodo de crisis económica que sería uno de los motivos principales para que se generara el movimiento revolucionario del país. Chihuahua resiente el cierre de minas, aserraderos y desempleo masivo. Asimismo, aumentaron las tarifas ferrocarrileras en el estado, en perjuicio de las pequeñas compañías y de los yacimientos con minerales de baja ley, ya que con las nuevas cuotas resultaba incosteable su transporte. Esta circunstancia provocó el cierre de varias compañías pequeñas. A su vez, en la primavera de ese mismo año cayó el precio de la plata y del cobre en el mercado mundial, y los principales inversores en la minería chihuahuense sufrieron una depresión económica que restringió seriamente su presencia en México. A mediados de 1907, las industrias ferrocarrileras y mineras del suroeste de Estados Unidos entraron también en crisis; Santa Eulalia, Parral y Santa Bárbara suspendieron su producción (Figura 4).
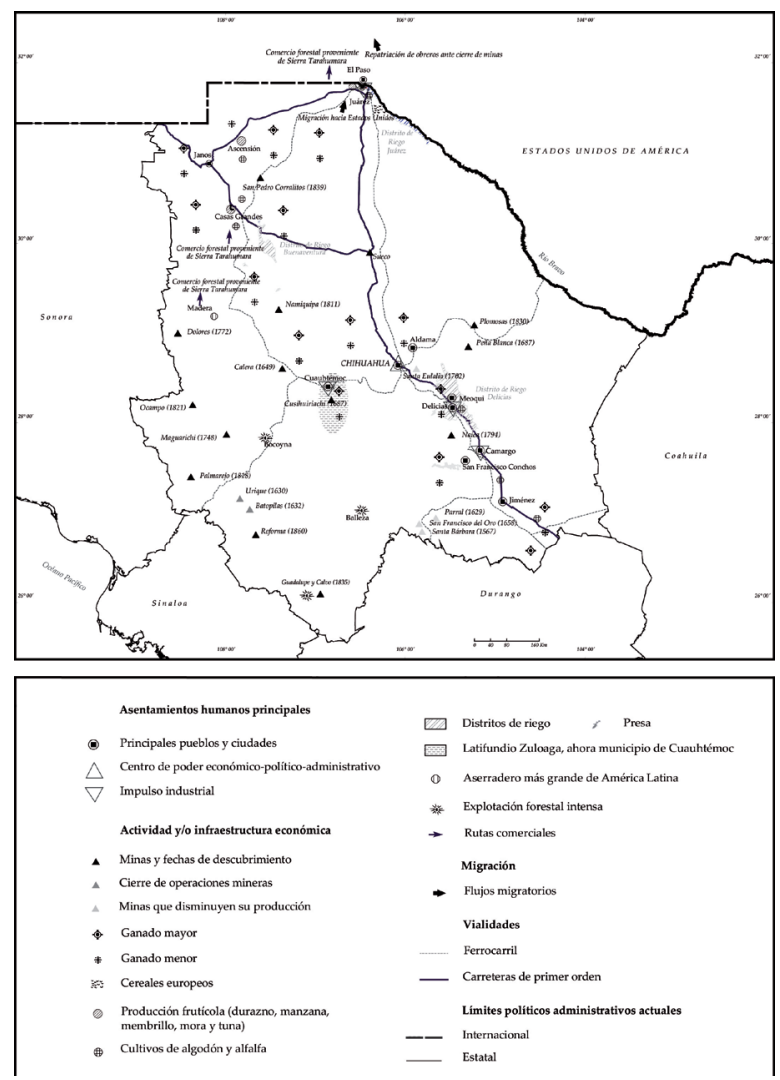

Fig 4. Chihuahua: actividades económicas 1907-1960

Fuente: elaboración con basada en Consejo de Recursos Minerales, op. cit; Lloyd, op. cit; Enríquez, op. cit. 
El cierre de varios complejos mineros de Arizona y Nuevo México generaron que cientos de mexicanos perdieran sus empleos. El despido masivo de dichos trabajadores, en condiciones precarias, obligó al gobierno nacional a instaurar un programa de repatriación a través de E1 Paso, Texas ${ }^{24}$

Entre 1908 y 1909 desparecieron casi por completo las pequeñas explotaciones mineras de la zona noroeste. La mayoría de los negocios del estado sufrieron un desequilibrio en sus operaciones y tuvieron que paralizar sus trabajos en perjuicio del comercio local, los empleados y los obreros. Desde luego, el resto de las ramas de la economía también se resintió por la crisis. Sólo se sobrepusieron algunos grupos de poder, como el grupo Terrazas, gracias a su diversificación, extensión y reservas de capital ${ }^{25}$.

En este contexto, el desarrollo urbano de la entidad se torna desequilibrado y contradictorio; las actividades productivas con sus reacomodos y tendencias marcan los cauces de este proceso que, por la orientación de los capitales, contribuye más a la pérdida que al rescate del territorio para beneficio social; la ocupación espacial se define por la desintegración y la desigualdad regional, así como por la irracionalidad en el uso de los recursos naturales. Ejemplo de lo anterior es la región de la sierra Tarahumara, a la que se dotó de la infraestructura necesaria para extraer sus recursos forestales, siendo incorporada a la función de abastecedora de materias primas sin importar su industrialización. Fue así como se instaló en Ciudad Madera el aserradero más grande de Latinoamérica y el ferrocarril se constituyó en un factor determinante para exportar materias primas, en esencia forestales, hacia los centros transformadores de la entidad, de la zona norte e, incluso, de los Estados Unidos de América, En contraposición, fue en los valles centrales de Chihuahua donde se llevó a cabo el proceso mayor de acumulación de capital y donde se concentraron las actividades económicas que ofrecían mejores y mayores posibilidades de producir a gran escala. Estos fenómenos le posibilitarían ser el centro de poder económico-político del Estado de Chihuahua ${ }^{26}$.

El resto de las regiones figuraron en este periodo con crisis en mayor o menor grado, según las ventajas económicas de su territorio. En Casas Grandes y Ascensión continuaron realizándose actividades de recolección, empaque y comercialización de durazno, manzana, membrillo, mora y tuna. Asimismo, llegó a ser importante para el mercado regional la producción de queso, alfalfa, leche, ganado vacuno y algodón ${ }^{27}$.

Fue en el periodo de 1910 a 1915 cuando empezó a superarse la crisis minera ante el repunte de los precios internacionales de la plata, el oro y el cobre, con lo que comenzaron a reflejarse en el territorio numerosas inversiones de capital hacia negocios madereros ${ }^{28}$. No obstante, la Sierra Tarahumara continuó con limitadas posibilidades

\footnotetext{
${ }^{24}$ Ibídem, p. 80.

${ }^{25}$ Orozco, 1991, p. 11.

${ }^{26}$ ENRÍQuez, 1988, p. 53.

${ }^{27}$ LLOYd, 2001, p. 32.

${ }^{28}$ El distrito de Galena fue el beneficiario principal de inversiones extranjeras y de miembros de la oligarquía chihuahuense quienes se enfocaron a la creación de infraestructura ferroviaria para el transporte de la producción maderera proveniente de la Sierra Madre Occidental. Es a finales de 1911 que se concluye la ampliación de la ruta ferroviaria del noroeste en el tramo de Casas Grandes a ciudad Madera, para conectar este enclave de explotación forestal con Ciudad Juárez-El Paso. Este hecho
} 
de expansión económica, pues su función se centraba en el abasto de materias primas para regiones que iban a ser impulsadas e incorporadas a la producción ${ }^{29}$.

Hacia 1920, después de 10 años de lucha continua, había en Chihuahua una postración social. La fuerza de trabajo campesina estaba dispersa, fragmentada o aniquilada. Muchos habían migrado a los Estados Unidos. Buena parte de la riqueza ganadera, agrícola e industrial formada durante la etapa anterior fue desmantelada ${ }^{30}$.

Entre 1921 y 1922 llegan a territorio chihuahuense algunas colonias de menonitas, grupos inmigrantes extranjeros de origen ucraniano, quienes logran establecerse gracias a permisos concedidos por el entonces gobierno federal de Álvaro Obregón. $\mathrm{Su}$ gobierno se mostró favorable al proyecto colonizador, dado que encajaba bien con las metas respecto a la inmigración extranjera a México, así como con sus intentos para reconstruir el país económicamente después de la lucha de 1910-1920. En lo particular a Obregón le interesaba la posibilidad de atraer a colonos extranjeros para ayudar en la tarea de revitalizar la agricultura, el sector de la economía que había experimentado más daños a consecuencia de la lucha armada. Así, unas de las principales colonias menonitas compran terrenos de la ex hacienda Bustillos, perteneciente a los herederos de Carlos Zuloaga y que se ubicaba cerca del pueblo de San Antonio de los Arenales (hoy Ciudad Cuauhtémoc), Chihuahua. Es a mediados de decenio de los años 20, durante el gobierno de Elías Calles, cuando se logran ver beneficios en el desarrollo económico de la región, gracias a la economía menonita que hace de San Antonio de los Arenales, un importante centro comercial del noroeste de Chihuahua ${ }^{31}$

Asimismo, durante los decenios de 1920 y 1930 se produjeron importantes movilizaciones campesinas que dieron lugar a los repartos agrarios que tomaron forma de colonias y ejidos. Con las nuevas tierras, los agraristas efectuaban labores agrícolas limitadas para sobrevivir puesto que no había posibilidades de trabajar con toda intensidad, ya que no se tenían ni conocimientos ni el capital necesario ${ }^{32}$.

En 1930, Lázaro Cárdenas decreta certificados de inafectabilidad agrícola y ganadera, lo cual permite, además de la dinamización de las actividades agropecuarias, el acceso a la monopolización por parte de grupos financieros que se beneficiaron de

convirtió a La Madera Compañía Ltd. de Pearson en uno de los principales productores mundiales de artículos forestales. LLOYD, 1991, p. 85.

${ }^{29}$ EnríQueZ, 1988, p. 57.

${ }^{30}$ Orozco, 1991, p. 16.

${ }^{31}$ La cantidad de los recursos colectivos de los menonitas, sus abundantes cosechas y las de los nuevos productores mexicanos de la región convirtieron a San Antonio de los Arenales -que en julio de 1927 fue elevado a la categoría de municipalidad con el nombre de Cuauhtémoc- en el mercado y punto de distribución de varios productos. Llegaron a establecerse en el pueblo una variedad de empresas y casas comerciales: hoteles, bancos, plantas embotelladoras de refrescos, ferreterías y talleres de refacción, expendios de combustible, etcétera. Con el dinero ganado con la exportación de los productos del campo se importaron artículos de consumo del centro del país y de Estados Unidos. TAYLOR, 2005, pp. 6-31; Almada, 1927, p. 443.

32 Orozco, 1991, p. 17; García, 2004, pp. 91-94. 
tales medidas ${ }^{33}$. Es así que ciudades como Cuauhtémoc, Delicias, Camargo y Juárez son impulsadas e inician su incipiente industrialización.

Desde 1940 comenzó a consolidarse un nuevo grupo económico dirigido por Eloy Vallina, quien fundó el Banco Comercial Mexicano, heredero de la banca porfirista chihuahuense. Gradualmente, este sector conformaría un poderoso conglomerado con inversiones de la industria maderera, cementera, de aceros, entre las principales. $\mathrm{Su}$ influencia en el ámbito de la economía alcanzaría también su correspondiente en la esfera de la política ${ }^{34}$.

La creciente sobreexplotación forestal llevó a que en el año 1947 se expidiera el decreto de veda total en el estado de Chihuahua. No obstante, dos años después se levanta la prohibición en la parte norte y sur de la zona forestal, dándosele la concesión a la Secretaría de Obras Públicas para que obtuviera durmientes para ferrocarril y postes de electrificación. Sin embargo, también continuaron las concesiones a particulares y grupos industriales. Tal es el caso del Grupo Chihuahua, que se había conformado gracias a la riqueza silvícola de la Sierra y a los negocios del ferrocarril. De 1946 a 1952 se dio mayor impulso a la iniciativa privada, así, este grupo de poder se fortalece pues el gobierno nacional concede alianzas a empresarios hasta llegar a controlar casi la totalidad de las actividades económicas del estado de Chihuahua. Hacia 1960 comienzó la explotación intensa de las áreas arboladas de Bocoyna, Balleza y Guadalupe y Calvo; este último, el municipio forestal más rico del país ${ }^{35}$.

La ganadería del estado, tan próspera en los años previos a la revolución, fue casi totalmente destruida durante el periodo revolucionario. El recurso para suplir la falta de ganado fue la importación y para impulsar la cría se organizaron exposiciones en donde se premiaba a los mejores especímenes y se procuraba el intercambio comercial y ganadero. La actividad pecuaria chihuahuense se mantuvo estática después del movimiento armado de 1910 hasta el año de 1930, cuando se inició una recuperación lenta pero gradual ${ }^{36}$

En 1929 se genera una nueva crisis económica mundial donde los precios de las mercancías y el comercio disminuyeron en forma drástica. La minería de Chihuahua reduce su producción, e incluso algunas minas cerraron totalmente sus puertas generándose un alto índice de desempleo. Aunque mermados, Parral, Santa Bárbara, San

${ }^{33}$ EnRíquez, 1988, p. 57.

${ }^{34}$ Orozco, 1991, p. 18.

${ }^{35}$ En esta época, las compañías industriales, principalmente mineras, recibieron del Estado autorización para extraer madera de los bosques ejidales pagando el derecho de monte que era un virtual subsidio para la industria. Este sistema rigió durante la sustitución de importaciones. Los ejidos, por su parte, al no realizar la explotación comercial del recurso no tenían un incentivo para su conservación y/o para ejercer el control sobre una explotación abierta. Durante los años sesenta, el gobierno estatal promovió las asociaciones en participación, que hacían que las comunidades fueran socias de compañías madereras. Así, los pequeños propietarios, ejidos y comunidades sólo podían venderle su producción al concesionario. Bajo presiones y descontento de los propietarios de los bosques, el sistema de concesiones se suspendió hasta que se modificó la ley forestal en 1986, confiriéndoles a las comunidades indígenas y ejidos la capacidad legal para tramitar sus propios permisos y disponer el aprovechamiento forestal. Domínguez, 2000, pp. 49, 55 y 167.

${ }^{36}$ García, 2001, p. 89. 
Francisco del Oro y Santa Eulalia (Aquiles Serdán) siguieron siendo los principales centros mineros, a diferencia de la Sierra donde la minería casi desapareció. Chínipas, Guazapares, Urique, Batopilas, por su parte, dejaron de ser atractivos para la inversión minera ${ }^{37}$.

Se observa una reconversión al interior de la entidad en cuanto a la modernización de la infraestructura regional, a raíz del cambio del patrón de la tenencia de la tierra. Se comienzan a abrir distritos de riego que aumentan la capacidad productiva agrícola. Es así como se fundan los distritos de riego de Delicias, Ciudad Juárez y San Buenaventura. Asimismo, se construyeron presas como La Boquilla, Ojo Caliente y Tintero $^{38}$. En 1940, Chihuahua contaba con $81 \%$ de las tierras recién abiertas al riego y con $50 \%$ de las nuevas carreteras construidas en México: se pavimentó el último tramo Ciudad Juárez-México, Villa Ahumada-Ciudad Juárez y se construyeron carreteras de General Trías a Villa Cuauhtémoc y de Parral a El Oro y Santa Bárbara ${ }^{39}$.

A diferencia de otros países, los efectos de la Segunda Guerra Mundial en México fueron favorables. La economía recibió un fuerte estímulo por los flujos de capital del exterior y por la posibilidad de emprender nuevos negocios. Los esfuerzos industrializadores del decenio de 1930 se fortalecieron por la demanda interna y externa. Comenzó el periodo de sustitución de importaciones y la idea de un país agrario quedó relegada. Las actividades agrarias debían subordinarse a la meta industrializadora. Los distritos de riego, en especial los del norte, debían producir mercancías para la exportación con el fin de obtener divisas destinadas a la compra de maquinaria e insumos industriales ${ }^{40}$.

La industria no había sido una actividad sustancial en la economía estatal, aunque existía una de carácter local compuesta por plantas despepitadoras de algodón y fábricas de textiles y de alimento (harina, trigo y bebidas). A partir de 1947, con la apertura de Cementos de Chihuahua, se inició un cambio industrial que incluyó la celulosa y la acerera ${ }^{41}$.

A través de la política de sustitución de importaciones, se da impulso a la industria del estado. Aunque esta política se cataloga como exitosa, genera un crecimiento desigual ya que la inversión indiscriminada de recursos tecnológicos, financieros y humanos en unos cuantos centros de población resulta la causa medular de la migración interna. Se forja entonces un acelerado poblamiento de los centros mayores; el gobierno y, en general, los sectores sociales más influyentes de la opinión pública estaban convencidos de que el futuro residía ya no en el campo sino en las ciudades, donde se hallaban las nuevas industrias que, por la concentración de la población en pequeños espacio geográfico, sería sencillo dotarla de infraestructura ${ }^{42}$. La población del estado crece sostenidamente de 1930 a 1960, con una tasa anual que aumenta de $2,5 \%$ al año hasta llegar a 3,7\% en su máximo crecimiento. A principios de la década

\footnotetext{
${ }^{37}$ Ibídem.

${ }^{38}$ VelázQuez, 1994, p. 184

${ }^{39}$ Delgado, 1999, p. 165.

40 Aboites, 2008, p. 491.

${ }^{41}$ Aвоiтes, 1994, p. 167

42 Aвоites, 2008, p. 484.
} 
de 1970, la población del estado era de 1.226.793; el 57\% residían ya en zonas urbanas, y el 70\% se concentraba en sólo cuatro ciudades: Ciudad Juárez, Chihuahua, Hidalgo del Parral y Delicias ${ }^{43}$. En esta etapa, se consolida la división política actual del estado de Chihuahua, al quedar conformada por 67 municipios distribuidos en $247.087 \mathrm{~km}^{2}$.

A nivel general, este periodo se caracteriza por diversas crisis sucesivas que no permitieron el despunte de las actividades económicas que se estaban gestando en el territorio chihuahuense. Desempleo, migración, cierre de actividades, polarización de la riqueza en unas cuantas manos, fueron las constantes en la dinámica social de la entidad.

\subsection{Chihuahua como destino de inversión extranjera directa orientado hacia el desarrollo del sector industrial (1960 - actualidad)}

A partir de 1961 se aplica una serie de programas de desarrollo regional en las franjas fronterizas del país, principalmente en el norte de México, cuya misión principal era la de suplir importaciones de productos industriales, fortalecer los intereses económicos entre las zonas fronterizas y el resto del país, alentar el turismo procedente del exterior, mejorar las condiciones socioeconómicas de las ciudades fronterizas, solucionar los problemas que enfrentaban la agricultura, la industria y el comercio. Nacen así instrumentos como el Programa Nacional Fronterizo, el Programa Industrial Fronterizo, el Programa de Fomento y Desarrollo Económico Fronterizo y el Programa Industrial para la Exportación ${ }^{44}$.

Comenzó a promoverse el establecimiento de plantas maquiladoras a lo largo de la frontera mexicana y a concederse estímulos y facilidades para el establecimiento de centros comerciales en las franjas fronterizas y en las zonas y perímetros libres del país; se instauró el programa de artículos de consumo fronterizo "gancho", que autorizaba a los comerciantes a importar, libres de impuestos, diversas mercancías a fin de complementar la oferta local ${ }^{45}$.

La actividad industrial de la entidad adquirió un gran dinamismo y para 1965 se inauguró un parque industrial fronterizo en Ciudad Juárez; para 1970 contaba con 22 plantas que empleaban 3.165 obreros. En 1974, las cifras habían aumentado a 89 plantas con 17.484 trabajadores y, para 1987, las plantas eran 252 con poco más de 95.500 obreros. Para este último año, las compañías se habían instalado en varias poblaciones del estado, preferentemente en la capital (47 plantas con 24.500 trabajadores) y en Delicias (seis plantas con 2.500 obreros). En 1988, Ciudad Juárez contaba con 10 parques industriales y, en 1992, aumentaron a $14^{46}$.

En 1989, en el país se viven diversos ajustes en política económica que permitieron la apertura de la mayoría de los sectores económicos a la inversión extranjera; para

\footnotetext{
${ }^{43}$ Instituto Nacional de Estadística y Geografía, 1963, pp. 23, 25.

${ }^{44}$ Gasca, 1999, p. 238; Delgado, 1999, p. 152.

${ }^{45}$ Ibídem, p. 153.

${ }^{46}$ GaSCA, 1999, p. 242; García, 2001, p. 108.
} 
1992, el 80\% de las empresas del estado de Chihuahua habían sido privatizadas ${ }^{47}$. El Tratado de Libre Comercio de América del Norte (TLCAN), firmado en 1994, es la culminación de esta política económica mexicana llamada "De apertura"48.

Actualmente las empresas que reciben inversión extranjera directa concentran más del $20 \%$ de toda la capacidad de empleo de México. En estados fronterizos, como Chihuahua, esta capacidad de empleo excede el 50\%. En términos de sectores económicos, las empresas manufactureras son líderes en inversión extranjera, seguidas por las financieras. Dentro de la industria fabril, el sector de la maquiladora acapara un tercio de toda la inversión extranjera ${ }^{49}$. Para 1998 , la industria manufacturera en Chihuahua contó con 9.917 unidades económicas, entre las que se encontraba la fabricación de estructuras metálicas, tanques y calderas; fabricación, reparación y/o ensamble de maquinaria y equipo para usos generales; y la fabricación y/o ensamble de maquinaria, equipo y accesorios eléctricos. También aparecían diseminados en barrios y localidades tortillerías, herrerías e imprentas. Asimismo, al considerar sólo las áreas urbanas y las correspondientes a las manufacturas, el comercio y los servicios privados, los municipios que destacan por personal empleado en estos rubros son Chihuahua, Juárez, Delicias y Cuauhtémoc ${ }^{50}$.

Asimismo, el movimiento maquilador afianzó las tendencias demográficas anteriores a 1970; es decir, consolidó la concentración de la población en las ciudades. Así, para 1990, dos municipios, el de la capital y Juárez, contaban con más de la mitad de los 2.442.000 habitantes del estado.

Para 1998, el valor de la producción minera fue de 3.309.544.000 pesos mexicanos, y 3.853 concesiones mineras (exploración, explotación y en trámite) cubrían el $23 \%$ de la superficie estatal. De igual forma, un total de 16 plantas de beneficio de minerales metálicos y 11 plantas de transformación de minerales no metálicos desarrollaron sus operaciones. La variación en los precios internacionales de los me-

\footnotetext{
${ }^{47}$ Quintín, 2002, p. 1.
}

${ }^{48}$ El planteamiento fundamental era encontrar el camino adecuado para insertarse en los mercados transfronterizos e internalizar el proceso de apertura económica mediante diversos ajustes como las ventas externas de productos, en algunas empresas, el mejoramiento de la productividad laboral, así como la actualización y modificación de las definiciones de negocios y nichos de mercado. La primera fase de apertura se encaminó por un proceso que incluyó la sustitución del mercado nacional por los mercados de exportación, de manera especial en la rama manufacturera y la desregulación comercial junto con la protección cambiaria. La segunda fase constó de la aplicación de una política de estabilización antiinflacionaria que giró alrededor del control de precios, la reestructuración de la deuda externa y el repliegue financiero del gobierno para liberalizar el proceso privado de ahorro e inversión, los tipos de cambio fijo o de flotación controlada, la modificación de la Ley de Inversión Extranjera y la atracción de la inversión foránea. Para los productores y autoridades estas medidas implicaban cambios tecnológicos, la competencia de productos importados, etc., y cuestionaron la existencia o viabilidad de empresas en la región fronteriza, ya que el crecimiento apresurado de la industria maquiladora en la frontera ofrecía atractivas oportunidades para ciertos sectores de la burguesía de ambos lados de la frontera, que se beneficiaría de este proceso, por diversos medios, la construcción, venta o renta de terrenos y naves industriales; la prestación de asesorías legal, financiera, contable y laboral; desarrollo de parques industriales y otros. Delgado, 1999, pp. 176-177.

${ }^{49}$ Quintín, 2002, p. 2.

${ }^{50}$ Instituto Nacional de Estadística y Geografía, 1999, p. 3. 
tales ha sido un factor fundamental para el incremento o disminución de la actividad minera. Actualmente destaca la producción de los distritos mineros de Moris, Batopilas, Ocampo, Naica, Parral, Bismark, Santa Eulalia, Terrenates y La Perla. A nivel nacional, la entidad obtuvo el primer lugar en producción de plomo, zinc, tungsteno y cadmio; el segundo lugar en plata; el tercer lugar en cobre y el quinto en oro ${ }^{51}$.

En algunas zonas de la entidad, la actividad agrícola se caracteriza por el alto desarrollo tecnológico y por la disponibilidad de recursos donde el algodón, el frijol, el maíz y el trigo son los principales productos agrícolas. No obstante, existen 25 municipios con unidades de producción agrícola cuya producción se destina al autoconsumo. La importancia del sector primario en la economía estatal, en lo que al PIB y a la población ocupada se refiere, perdió importancia durante los últimos 30 años. La población ocupada en el sector primario disminuyó de manera considerable al pasar de 39\% a 9\% entre 1970 y 2000; por el contrario, la población ocupada en el sector secundario creció un $100 \%$ al pasar de $22 \%$ al $44 \%{ }^{52}$.

Las condiciones sociales que imperaron en este periodo son un reflejo directo de las políticas económicas que se privilegiaron. El emplazamiento de numerosas industrias generó un efímero estado de bienestar para la población de Chihuahua, que se constató en el empleo y los ingresos. Hoy en día perviven condiciones de volatilidad laboral, dado que la inversión extranjera directa, al estar sujeta a los vaivenes de la economía y a las condiciones de competitividad, no generan arraigo territorial, y son pocas las empresas mexicanas que logran sustentar la economía.

Actualmente, el estado de Chihuahua posee una población de 3.401 .140 personas y su Producto Interno Bruto (PIB) asciende a poco más de 370.000.000.000 de pesos que constituyen el 3.5\% del total nacional. El 53\% de su PIB está enfocado a las actividades comerciales y de servicios, $40 \%$ a las industriales, y $7 \%$ a las primarias. El estado presenta fortalezas significativas, puesto que es la $12^{\text {va }}$ economía del país. Captó para 2008, 1.121.000 de dólares por concepto de inversión extranjera directa, representando el 5\% del total recibido en México. Ocupa el primer lugar nacional en personal ocupado por la industria manufacturera de exportación. Entre las principales actividades económicas de Chihuahua se posiciona la industria forestal, la más amplia y mejor integrada del país. En el área industrial, la producción más importante proviene de las plantas maquiladoras de la pequeña y mediana industria de transformación, Se encuentra entre los primeros cinco estados del país por su ingreso per cápita y por su índice de desarrollo humano; tiene el segundo lugar nacional en ingresos propios $^{53}$

\section{CONCLUSIONES}

La realización de un reconocimiento de actividades económicas y su influencia espacial a lo largo de las cuatro etapas históricas identificadas permitió mostrar territorios

${ }^{51}$ Consejo de Recursos Minerales, 1998, pp. 2-8.

${ }^{52}$ Bustillos, 2003, pp. 513-522.

${ }^{53}$ Instituto Nacional de Estadística y Geografía, 2010, pp. 34-40; Instituto Mexicano para la Competitividad, 2008, p. 130. 
con vocaciones económicas arraigadas, otros dotados con infraestructuras que posibilitan su óptimo desenvolvimiento, algunos con intensos vínculos comerciales y arraigo cultural, y otros preferentes para la inversión extranjera, contraponiéndose a aquellos espacios con nula asimilación económica que presenta el territorio chihuahuense.

Las actividades económicas que han sido soporte de la economía estatal han estado sujetas a intensas fluctuaciones, respondiendo directamente a los ciclos económicos mundiales. Ello ha ocasionado que, actividades tradicionales como la agricultura, la minería, el aprovechamiento forestal o la industria maquiladora hayan sobrellevado periodos de intensas crisis que las situaron al borde de la desaparición o bien, hayan disfrutado de tiempos de bonanza y consecuente creación y mejora de infraestructura para su desarrollo. Asimismo, las políticas económicas privilegiadas por sexenios han dado lugar a la creación de grupos de poder que han mantenido el control de ciertas actividades económicas a lo largo de la historia económica de la entidad, observándose la polarización de la riqueza en unas cuantas manos y la acentuación de la pobreza en los sectores menos afortunados.

\section{REFERENCIAS BIBLIOGRÁFICAS}

Aboites, Luis

1994 Breve historia de Chihuahua. México. El Colegio de México-Fondo de Cultura Económica.

2008 “El último tramo 1929-2000”. En Nueva Historia Mínima de México. México. Secretaría de Educación del Gobierno del Distrito Federal - El Colegio de México, pp. 469-538.

Almada, Francisco

1927 Diccionario de Historia, Geografia y Biografía Chihuahuenses. México. Talleres Gráficos del Gobierno del Estado de Chihuahua.

Almada, Francisco y Chávez, Armando

1987 "El norte: Chihuahua". En PIÑERA RAmírez, David. Visión histórica de la frontera norte de México. De los aborígenes al septentrión novohispano. Tomo II. México. Universidad Autónoma de Baja California-Centro de Investigaciones Históricas de la Universidad Nacional Autónoma de México, pp. 3-14.

BAssols, Ángel (coord.)

1999 La gran frontera. Franjas fronterizas México - Estados Unidos. Transformaciones y problemas de ayer y hoy. Tomo II. México. Instituto de Investigaciones Económicas -Universidad Nacional Autónoma de México. 
Bustillos, Sandra

2003 "La agricultura". En Orozco, Víctor (coord.). Chihuahua Hoy 2003.

Visiones de su historia, economía, politica y cultura. México. Universidad Autónoma de Ciudad Juárez, pp. 501-522.

Camelo, Rosa

1990 "Nueva España: siglos XVII y XVIII". En Atlas Nacional de México. México. Instituto de Geografía - Universidad Nacional Autónoma de México, hoja II.2.2.

CÁRDENAS, Lázaro

1972 Obras de Lázaro Cárdenas: apuntes 1913-1940. Tomo I. México. Universidad Nacional Autónoma de México - Nueva Biblioteca Mexicana.

CARrera, Carlos

1989 Urbanización del espacio chihuahuense, evolución y contradicciones. Tesis de licenciatura. México. Escuela de Arquitectura de Chihuahua.

Castellanos, Alicia

1981 Ciudad Juárez, la vida fronteriza. México. Editorial Nuestro Tiempo.

Commons, Áurea

1990 "Divisiones territoriales: 1810-1990". En Atlas Nacional de México. México. Instituto de Geografía - Universidad Nacional Autónoma de México, hoja II.3.1.

CONSEJO NACIONAL DE POBLACIÓN

1985 Chihuahua demográfico. Breviario. México. Consejo Nacional de Población.

Consejo de Recursos Minerales

1992 Monografia Geológico-Minera del Estado de Chihuahua. México. Editorial Pedagógica Iberoamericana.

1998 Panorama minero del Estado de Chihuahua. México. CRM - Oficina Regional Chihuahua.

De la Fuente, Beatriz

1994 México en el mundo de las colecciones de arte. Mesoamérica. Tomo 2. México. Secretaría de Relaciones Exteriores - Universidad Nacional Autónoma de México - Consejo Nacional para la Cultura y las Artes.

Delgado, Irma

1999 "Economía, integración y cambio". En BAssols (coord.), pp. 149-194. 
Domínguez, Lilia

2000 "Complejo forestal mexicano: principales retos". En EsCALANTE, Roberto - Aroche, Fidel (comps.). Sector forestal mexicano: paradojas de la explotación de un recurso natural. México. Universidad Nacional Autónoma de México-Facultad de Economía, pp. 153-225.

ENRíQUEZ, Jorge

1988 Análisis Geoeconómico del Sistema Regional de la Sierra Tarahumara. México. Universidad Nacional Autónoma de México.

GaScA, José

1999 "El medio ambiente en el desarrollo fronterizo". En BAssols (coord.), pp. 231- 263.

GARCíA, Bernardo

2004 "El desarrollo regional, siglos XVI al XX". En Semo, Enrique. Historia económica de México. México. Universidad Nacional Autónoma de México - Editorial Océano, pp. 7-107.

GARCÍA, María Luisa

2001 Niveles de asimilación económica y estructura urbana de Chihuahua. Tesis de doctorado. México. Facultad de Filosofía y Letras - Universidad Nacional Autónoma de México.

Gerhard, Peter

1996 La frontera norte de la Nueva España. México. Universidad Nacional Autónoma de México.

Gómez, Josefina, et al.

1982 El pensamiento geográfico. Madrid. Alianza Editorial.

HERNÁNDEZ, Jorge

1966 Atlas Porrúa de la República Mexicana. México. Editorial Porrúa.

Instituto MeXicano para la Competitividad

2008 "Chihuahua. Realidad: análisis IMCO". En Índice de Competitividad Estatal 2008: Aspiraciones y realidad. México. Instituto Mexicano para la Competitividad, A. C., pp. 125-135.

Instituto Nacional de Estadística y Geografía

1963 VII Censo General de Población 1960. Estado de Chihuahua. México. Secretaría de Industria y Comercio. Dirección General de Estadística.

1999 Imágenes Económicas del Estado de Chihuahua. México. Instituto Nacional de Estadística y Geografía.

2010 Sistema de Cuentas Nacionales de México. Producto Interno Bruto por entidad federativa, 2003-2008. Año base 2003. Segunda Versión. México. Instituto Nacional de Estadística y Geografía. 
LLOYD, Jane-Dale

2001 Cinco ensayos sobre cultura material de rancheros y medieros del noroeste de Chihuahua, 1886-1910. México. Universidad Iberoamericana

- Departamento de Historia.

MonTAÑo, Jorge

1979 Los pobres de la ciudad en los asentamientos espontáneos. México. Siglo XXI Editores.

Orozco, Víctor

1991 Chihuahua. Sociedad, Economía, Política y Cultura. México. Biblioteca delasEntidades Federativas-CentrodeInvestigacionesInterdisciplinarias en Humanidades - Universidad Nacional Autónoma de México.

1992 Las guerras indias en la historia de Chihuahua. Antología. México. Universidad Autónoma de Ciudad Juárez. Instituto Chihuahuense de Cultura.

Propin, Enrique

2003 Teorías y métodos en Geografía Económica. México. UNAM - Instituto de Geografía.

Quintín, Erwan

2002 “México está listo para rugir?” Southwest Economy. Septiembreoctubre. Federal Reserve Bank of Dallas. Documento digital disponible en: http://dallasfed.org/entrada/articles/2002/sp_swe0205a.html

SAnTos, Milton

1985 Espaçio e Método. Sau Paulo. Livraria Editora Nobel.

TAYLOR, Lawrence

2005 "Las migraciones menonitas al norte de México entre 1922 y 1940". Migraciones Internacionales. México. vol. 3:1, pp. 5-31.

VÁzQuEZ, Carmen

1990 "Rebeliones y revueltas. Las luchas rurales 1820-1910". En Atlas Nacional de México. México. Instituto de Geografía - Universidad Nacional Autónoma de México, hoja II.5.4.

VelázQuez, Catalina

1994 "Evolución de la frontera, de Cárdenas a la Segunda Guerra Mundial. 1934-1945”. En PIÑERA Ramírez, David. Visión histórica de la frontera norte de México. Tomo V. México. Universidad Autónoma de Baja California - Editorial Kino-El Mexicano, pp. 173-252. 